\title{
Relation between psychiatric disorder and abnormal illness behaviour in patients undergoing operations for cervical discectomy
}

\author{
Ruth E Taylor, Francis Creed, David Hughes
}

\begin{abstract}
Objective-To test the hypothesis that depression in patients being considered for cervical disc surgery is associated with severe organic pathology. Secondly, to test whether depression and abnormal illness attitudes recorded preoperatively would predict poorer recovery.

Methods-Seventy four patients with pain and disability from cervical arthrosis were examined during investigations before potential cervical surgery. The prevalence of psychiatric disorder was assessed using the SCAN, and attitude to illness using the illness attitude scale.

Results-There was a rate of depressive disorder in the sample of $37 \%$. The depressed patients did not have more severe organic pathology, more neurological symptoms or signs, or more disablement. They reported more pain and displayed more abnormal illness behaviour. Fifty patients went on to cervical surgery. Outcome four to eight months postoperatively was not related to the presence of psychiatric disorder or illness attitude recorded preoperatively.

Conclusion-Depressive disorder is not secondary to severe pathology; the outcome of surgery is predominantly determined by physical factors.
\end{abstract}

(F Neurol Neurosurg Psychiatry 1997;63:169-174)

Keywords: cervical spine surgery; abnormal illness behaviour; psychiatric disorder

University

Department of

Psychiatry,

Manchester Royal

Infirmary, Manchester,

UK

R E Taylor

F Creed

Hope Hospital, Stott

Lane, Salford, UK

D Hughes

Correspondence to: Dr RE Taylor, Department of Psychiatry, Institute of Psychiatry, De Crespigny Park, Denmark Hill, London SE5 8AF, UK.

Received 1 August 1996 and in final revised form 21 February 1997

Accepted 25 February 1997

The influence of psychological variables in lumbar spinal surgery for low back pain has been extensively researched; psychological and social factors contribute significantly to the outcome $^{1}$ and now contribute to selection of patients for surgery. ${ }^{2-3}$ Little parallel research exists into the outcome of patients undergoing surgery on the cervical spine for neck pain, radiculopathy, and myelopathy due to cervical degenerative disease. Only one study has investigated psychological factors in the treatment of cervical arthrosis. ${ }^{4}$

Like lumbar disc surgery there is a wide variation in outcome reported for cervical surgery. A review of outcome studies by Ehni ${ }^{5}$ concluded that radiculopathy may essentially be cured in about two thirds of cases, with lesser degrees of benefit in one fifth and unsatisfac- tory results in one tenth. For myelopathy he estimates that about $70 \%$ receive some benefit.

Table 1 shows that recent studies have produced variable results and no study has used independent or objective measures of outcome.

No studies have attempted to examine the factors that determine variation in outcome in cervical spine surgery, by contrast with the many studies in lumbar surgery ${ }^{236-8}$ In these studies of lumbar disc surgery the psychological measures that have been used to predict outcome are (a) personality, predominantly MMPI $^{136} ;(b)$ health attitudes and abnormal cognitions $^{79}$; (c) abnormal illness behaviour. ${ }^{2} 8$

None of these studies examined the effect of depressive disorder which often accompanies chronic pain. Such depression requires assessment by research interview as the validity of self administered questionnaires is questionable in these circumstances. ${ }^{10}$

Waddell et al showed that in patients with low back pain high levels of distress were associated with abnormal illness behaviour which was reduced if the patients benefited from surgery. These findings suggested that depression is secondary to the pain and disability arising from the lumbar disc pathology.

The present study was performed to test the hypothesis that depression in patients being considered for cervical disc surgery was associated with severe organic pathology. Secondly, it was hypothesised that depression and abnormal illness attitudes recorded preoperatively would predict poorer recovery.

\section{Method}

PATIENTS

The patients for this study were ones admitted consecutively to the neurosurgical wards at Hope Hospital, Manchester Royal Infirmary, and North Manchester General Hospital, either for cervical surgery or for investigation of possible cervical pathology with a view to surgery. Patients with rheumatoid neck disease, neoplasia, or acute trauma were excluded. different neurosurgeons. Preoperative assessments were done between February and August 1992. The follow up assessments were done in the six months from August 1992 to February 1993.

PREOPERATIVE ASSESSMENT

Patients were seen immediately before surgery or investigation. The following measures were obtained: Patients were under the care of one of seven 


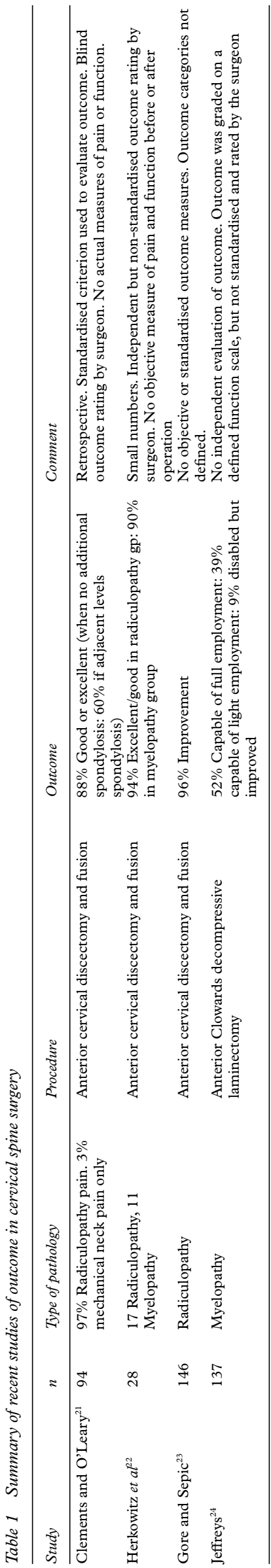

Psychiatric morbidity

This was determined using the SCAN $^{11}$ interview (Schedules for Clinical Assessment in Neuropsychiatry World Health Organisation 1992; PSE10) which is a research tool involving a full standardised assessment of mental state over the previous month.

Physical morbidity

(a) Neurological symptoms were measured by asking patients to complete a chart outlining on a picture of the body areas where they experienced paraesthesiae, numbness, weakness, and pain. These were rated as mild, moderate, severe, and very severe. Any symptoms which were not deemed by the neurosurgeons to constitute part of the typical clinical picture for a radiculopathy or myelopathy were recorded as a count of atypical symptoms.

(b) Neurological signs were measured using objective neurological signs (sensory loss, weakness, and loss of reflexes) recorded preoperatively by the neurosurgeon.

(c) Pain was measured using the short form of the McGill pain questionnaire (SF-MPQ) ${ }^{12}$

(d) Disability was measured using the functional limitation profile (FLP) ${ }^{13}$

(a standardised validated English version of the American sickness impact profile $\left.{ }^{14}\right)$. It produces three scores: a physical, a psychosocial, and an overall score.

(e) Organic pathology was assessed by an independent consultant neuroradiologist who rated CT myelograms and plain radiographs for spinal intervertebral disc and bony pathology, and associated medullary and nerve root compression. The level where the severest pathology was present was recorded. Ratings were also made of the consistency of the radiological findings with the clinical picture and operative findings.

( $f$ ) Attitude to illness was measured using the illness attitude scales (IAS) of Kellner ${ }^{15}$ as it measures relatively enduring traits independent of psychiatric disorder.

OUTCOME OF SURGERY

Patients were reassessed at least three months postoperatively and outcome was measured as:

(1) Patients' rating on a five point scale, specific operationalised criteria were provided for each category (details available on request). In the analysis of the outcome the very good and improved categories were compared with same and worse.

(2) Improvement in pain level was measured by a further administration of the short form of the McGill pain questionnaire; the postoperative score was subtracted from the preoperative score to produce a change score.

(3) Reduction of disability was measured by asking patients to complete the FLP again postoperatively and then subtracting the postoperative from the pre-perative score.

ANALYSIS OF RESULTS

Subjects were divided into those with and without psychiatric disorder as assessed by the preoperative SCAN (PSE 10). They are referred to as "cases" and "non-cases". 
Table 2 Case v non-case demographic and clinical variables

\begin{tabular}{|c|c|c|c|c|c|}
\hline Variable & $\begin{array}{l}\text { Non-cases } \\
(n=46) n(\%)\end{array}$ & $\begin{array}{l}\text { Cases }(n=27) n \\
(\%)\end{array}$ & $\chi^{2}$ & $d f$ & P value \\
\hline Employed/housewife/student & $24(52 \%)$ & $6(22 \%)$ & & & \\
\hline $\begin{array}{l}\text { Not working due to cervical problems (sickness benefit/early } \\
\text { retired) }\end{array}$ & $12(26 \%)$ & $18(67 \%)$ & & & \\
\hline Not working other (retired/unemployed) & $10(22 \%)$ & $3(11 \%)$ & 11.61 & 2 & $0.003^{\star \star}$ \\
\hline \multicolumn{6}{|l|}{ History: } \\
\hline$<6$ months & $4(9 \%)$ & $3(11 \%)$ & & & \\
\hline 6-12 months & $9(20 \%)$ & $4(15 \%)$ & & & \\
\hline $1-2$ years & $11(24 \%)$ & $7(26 \%)$ & & & \\
\hline$>2$ years & $11(24 \%)$ & $8(30 \%)$ & 0.79 & 4 & 0.94 \\
\hline$>5$ years & $11(24 \%)$ & $5(19 \%)$ & & & \\
\hline \multicolumn{6}{|l|}{ Drugs: } \\
\hline NSAIAs & $10(22 \%)$ & $12(44 \%)$ & 3.16 & 1 & 0.08 \\
\hline Narcotics & $12(26 \%)$ & $17(63 \%)$ & 8.18 & 1 & 0.004 \\
\hline Non-narcotic analgesic & $6(13 \%)$ & $7(26 \%)$ & 1.14 & 1 & 0.28 \\
\hline Tranquillisers & $2(4.3 \%)$ & $2(7.4 \%)$ & 0.00 & 1 & 0.98 \\
\hline Antidepressants & $3(6.5 \%)$ & $6(22 \%)$ & 2.56 & 1 & 0.11 \\
\hline Night sedation & $1(2.2 \%)$ & $9(33 \%)$ & 11.46 & 1 & $<0.001^{\star \star \star}$ \\
\hline Not taking analgesics & $22(51 \%)$ & $2(7 \%)$ & & & \\
\hline Exceeds dose analgesics & $5(11 \%)$ & $12(71 \%)$ & & & \\
\hline Does not exceed dose & $16(37 \%)$ & $13(48 \%)$ & 17.10 & 2 & $<0.001^{\star \star \star}$ \\
\hline Wearing collar & $10(22 \%)$ & $7(26 \%)$ & 0.01 & 1 & 0.90 \\
\hline Using stick & $7(15 \%)$ & $3(11 \%)$ & 0.02 & 1 & 0.89 \\
\hline Using frame & $1(2 \%)$ & $0(0 \%)$ & 0.00 & 1 & 1.00 \\
\hline Using wheelchair & $3(7 \%)$ & $1(4 \%)$ & 0.00 & 1 & 1.00 \\
\hline Using other aids & $0(0 \%)$ & $1(4 \%)$ & 0.07 & 1 & 0.79 \\
\hline Psychiatric history & $4(9 \%)$ & $6(22 \%)$ & 1.60 & 1 & 0.20 \\
\hline Family psychiatric history & $8(17 \%)$ & $3(11 \%)$ & 0.15 & 1 & 0.70 \\
\hline Recent major psychosocial stress apart from neck problem & $1(2 \%)$ & $4(15 \%)$ & 2.50 & 1 & 0.11 \\
\hline
\end{tabular}

NSAIAs $=$ non-steroidal anti-inflammatory agents

The data were analysed with the statistical package for the social sciences (SPSS). As many of the data were not normally distributed, non-parametric statistical tests were chosen; significant differences were assessed by comparing cases with non-cases using $\chi^{2}$ tests for categorical variables and Mann-Whitney $U$ tests for continuous variables.

For the association between preoperative IAS scores and outcome Kruskal-Wallis tests were used for categorical outcome variables and Kendall's correlations for continuous outcome variables. Many comparisons were made in examining this part of the hypothesis, and so readers may wish to take a Bonferroni adjustment into account.

\section{Results}

Seventy four patients were assessed and included in the study, but the SCAN was not completed for one of them. There were 46 males and 28 females. In their clinical presentation the patients fell broadly into the following groups: those with myelopathy (symptoms and signs of cord compression; $n=13$ ); those with radiculopathy (symptoms and signs of root compression; $n=43$ ); and a group with features of both $(n=7)$. There were also six patients in whom the clinical picture was definitely atypical and five in whom it was unclear. Forty one patients were assessed before operation. Thirty three were assessed before investigation, nine of whom went on to have operations. The only significant difference between patients assessed before investigation and those assessed before surgery was on the physical subscale of the FLP, in which the preoperation group showed greater physical disability (mean rank scores preoperative group 41.42, preinvestigation group 30.34, $\mathrm{P}=0.02$ ). Fifty out of the 74 patients in the study went on to have surgery and of these follow up was achieved in 48 (96\%).
Fifty eight per cent $(n=29)$ underwent an anterior clowards operation, $8 \% \quad(n=4)$ an anterior microdiscectomy, $28 \% \quad(n=14)$ a posterior decompressive laminectomy, and the remaining three had variants of these procedures.

RESULTS OF SCAN EXAMINATION

Twenty seven of the 73 patients $(37 \%)$ were definite cases of psychiatric disorder (index of definition of 5 or more $)^{16}$ Most had depressive disorders of varying severity: five had moderate depression, 16 had mild depression, five had neuraesthenia, and one agrophobia.

Tables 2-4 compare patients with and without psychiatric disorder at first assessment (cases and non-cases).

There were no significant differences between cases and non-cases according to the hospital where they were treated; whether they were assessed at hospital or at home; their age; their sex; their marital status; and whether or not they were seen before operation or investigation.

Cases of psychiatric disorder were less likely to be working, and more likely than non-cases to be taking excessive analgesia (table 2). They reported significantly more atypical symptoms than the non-cases, and had tried more treatments (table 3).

There were no significant differences between cases and non-cases in the subjective symptoms recorded on the body chart or in the objective neurological signs recorded on examination.

Cases scored significantly higher than noncases on the psychosocial dimension of the FLP and reported more pain (table 4).

On the preoperative illness attitude scale (IAS scores) the only significant differences between cases and non-cases were that the cases scored significantly higher on the thana- 
Table 3 Mann-Whitney tests: cases v non-cases, clinical variables

\begin{tabular}{llll}
\hline Variable & $\begin{array}{l}\text { Non-cases (n=46) } \\
\text { median (range) }\end{array}$ & $\begin{array}{l}\text { Cases (n=27) } \\
\text { median (range) }\end{array}$ & P value \\
\hline Age & $52(42-61)$ & $49(40-50)$ & 0.31 \\
$\begin{array}{l}\text { Conditions requiring admission to hospital in } \\
\quad \text { the past }\end{array}$ & $2(1-3)$ & $2(1-3)$ & 0.35 \\
No of doctors consulted with neck problem & $3(2-3)$ & $3(3-4)$ & 0.14 \\
No of other treatments tried & $1(0-3)$ & $2(1-4)$ & 0.035 \\
No of atypical symptoms & $0(0-1)$ & $2(0-3)$ & 0.007 \\
\hline
\end{tabular}

Values are median (interquartile range).

Table 4 Mann-Whitney tests: cases $v$ non-cases on overall FLP function scores, and McGill pain scores

\begin{tabular}{llll}
\hline Variable & $\begin{array}{l}\text { Non-cases }(n=46) \\
\text { median (range) }\end{array}$ & $\begin{array}{l}\text { Cases }(n=27) \\
\text { median (range) }\end{array}$ & P values \\
\hline FLP dimensions: & $23(10-33)$ & $29(20-36)$ & 0.25 \\
$\quad$ FLP physical dimension & $23(12-30)$ & $34(21-46)$ & 0.001 \\
$\quad$ FLP psychosocial dimension & $22(13-27)$ & $31(22-35)$ & 0.008 \\
$\quad$ FLP overall score & $9(4-16)$ & $17(9-23)$ & 0.001 \\
McGill pain questionnaire: & $34(22-50)$ & $52(40-55)$ & 0.006 \\
$\quad$ Total score & Visual analogue score & &
\end{tabular}

Values are median (interquartile range).

Table 5 Mann Whitney tests: cases $v$ non-cases on severity of pathology rated on radiological investigations

\begin{tabular}{|c|c|c|c|}
\hline Variable & Non-cases $(n=42)$ & Cases $(n=22)$ & $P$ values \\
\hline Total severity root entrapment score & $4 \quad(2-7)$ & $1.5(0-3.25)$ & 0.003 \\
\hline Total severity foraminal stenosis score & $0.5(0-4)$ & $1 \quad(0-1)$ & 0.53 \\
\hline $\begin{array}{l}\text { Combined total severity stenosis and root } \\
\text { entrapment }\end{array}$ & $(2-9.25)$ & $(0-4.25)$ & 0.006 \\
\hline Total score on severity disc degeneration & $5 \quad(3.75-7)$ & $(1-6)$ & 0.01 \\
\hline $\begin{array}{l}\text { Total number of levels affected by degenerative } \\
\text { disease }\end{array}$ & $3 \quad(2-3)$ & $1.5(1-3)$ & 0.01 \\
\hline
\end{tabular}

Values are median (interquartile range).

Table 6 Comparison of the three main outcome measures between preoperative cases and non-cases with $\chi^{2}$ tests

\begin{tabular}{lccccc}
\hline Variable & $\begin{array}{l}\text { Non-cases } \\
n(\%)\end{array}$ & $\begin{array}{l}\text { Cases }(n=19) \\
n(\%)\end{array}$ & $\chi^{2}$ & $d f$ & P value \\
\hline Patient rated outcome: & $19(65.5)$ & $13(68.4)$ & & & \\
$\quad$ Improved & $6(20.7)$ & $4(21.1)$ & 0.113 & 2 & 0.94 \\
$\quad$ Same & $4(13.8)$ & $2(10.5)$ & & & \\
$\quad$ Worse & & & & \\
Change in McGill total pain & $17(58.6)$ & $15(78.9)$ & & & \\
$\quad$ score: & $3(10.3)$ & $2(10.5)$ & 2.818 & 2 & 0.24 \\
$\quad$ Improved & $9(31.0)$ & $2(10.5)$ & & & \\
$\quad$ Same & $19(65.5)$ & $14(73.7)$ & 0.356 & 1 & 0.55 \\
$\quad$ Worse & 0 & 0 & & & \\
Change in FLP overall score: & $10(34.5)$ & $5(26.3)$ & & & \\
$\quad$ Improved & & & & \\
$\quad$ Wame & & &
\end{tabular}

taphobia scale $(\mathrm{P}<0.01)$, on the worry scale $(\mathrm{P}<0.05)$, and on the treatment experience scale $(\mathrm{P}=0.01)$.

Patients with psychiatric disorder showed no differences from non-cases on levels of physical disability, and neurological symptoms and signs, and they had less severe pathology as rated objectively on radiological investigations (table 5).

RESULTS OF FOLLOW UP ASSESSMENTS: OUTCOME OF SURGERY

Fifty of the 74 patients initially included went on to have surgery, of whom 19 (38\%) had preoperative psychiatric disorder (a similar proportion to that in the original sample of 74).

Table 6 displays the outcome by preoperative psychiatric disorder for the three main outcome measures. There was no significant difference between cases and non-cases on any of the main outcome measures. There were also no differences between cases and noncases on other outcome variables - for example, the proportions returning to work (both of which were low: $10 \%$ cases, $21 \%$ non-cases), experiencing postoperative complications, reporting atypical symptoms, or taking analgesia.

The only significant associations between preoperative illness attitude scales and postoperative outcome were a significant correlation between high scores on bodily preoccupation and failure to improve on the physical dimension of the FLP $(\mathrm{P}=0.008)$; and between a high score on thanatophobia and failure to improve on the psychosocial dimension of the FLP $(P=0.009)$. These were two out of 180 correlations and may have occurred by chance.

In summary, there was no association between preoperative psychiatric caseness or illness attitude scale scores and postoperative outcome.

\section{Discussion}

METHODOLOGICAL PROBLEMS

There are several methodological problems which need to be considered before discussing the interpretation of the results. Firstly, the sample of 74 patients was not homogenous but included a mixture of patients with radiculopathy, in whom the principal symptoms were pain, and patients with myelopathy who had less pain but usually more disability often involving loss of mobility. These differences place some limitations on the strength of the conclusions of this study, but most patients did experience cervical pain, sensory symptoms, and neurological impairment due to a degenerative process in the spine, and most underwent a similar neurosurgical procedure aimed at reducing these symptoms.

Although some patients were seen before surgery and some before investigation these groups only differed in that the first had greater physical disability as measured by the FLP. As the hypotheses involve examining the relation between depression, physical symptoms, function, and pain it is not problematic to combine patients with a range of severity.

The assessment of surgical outcome was not straightforward; no single measure of outcome has yet been established for this population. We therefore employed measures of outcome based on the patients' own ratings of overall outcome together with standardised measures of pain and disability (McGill and FLP). The pattern of outcome was similar with these different measures. The proportion of patients improving on all three measures was between two thirds and three quarters, which is comparable with $\mathrm{Ehni}^{5}$ who concluded that radiculopathy may be cured in two thirds of patients.

PREOPERATIVE ASSESSMENTS AND TESTING OF THE FIRST HYPOTHESIS

The proportion of patients found to be have a psychiatric disorder $(37 \%)$ is high compared with rates reported in other medical and surgical populations using research interviews ${ }^{17}$ but is comparable with rates reported in patients with lumbar pain. (For example, Krishnan et $a l^{18}$ found a rate of depressive illness as defined 
by research diagnostic criteria of $44 \%$ in a sample of patients with chronic low back pain.)

The results of the preoperative assessment do not support the first hypothesis. Patients with psychiatric disorder do not have more neurological symptoms or signs; nor do they have more physical disability as measured by the physical dimension of the FLP.

The finding that psychiatric cases have significantly less objective degenerative disease and severity of root entrapment on radiology (table 5) is noteworthy because it refutes the hypothesis that the development of depressive disorder is secondary to the organic disease. Rather, it is likely that the development of a depressive illness leads to an increase in perception and complaints of pain.

If a depressive illness is responsible for the higher levels of pain perceived by these patients, and for their increased psychosocial disability, it is possible that treatment for the depression might improve their symptoms, possibly even to the point that surgery could be avoided, given the lesser degree of organic pathology in some of these patients.

The suggestion that the development of depression is related to chronicity of pain is not supported by this study.

It is interesting that comparing cases and non-cases on their symptoms, there is no difference on clear symptoms of radiculopathy - that is, paraesthesiae, numbness, and weakness-but cases complain significantly more of atypical symptoms than do non-cases (table 3 ) which may be a manifestation of abnormal illness behaviour. The finding that cases were significantly more likely to exceed the dose of analgesia (table 2), and to have tried more treatments (table 3) may also reflect abnormal illness behaviour. This again supports the notion of Main and Waddell ${ }^{9}$ that abnormal illness behaviour is related to psychological distress. The higher psychosocial and employment disability may also reflect abnormal illness behaviour in the cases.

FOLLOW UP ASSESSMENTS AND TESTING OF THE SECOND HYPOTHESIS

This study has found that the results for cervical surgery are comparable with those found in lumbar surgery. Our hypothesis that depressive disorder would predict a poor outcome was not supported; similarly, the prediction that abnormal illness attitudes would predict a poor outcome was not supported. Radanov et $a l^{19}$ also found that recovery from whiplash was independent of psychosocial factors. Waddell et $a l^{8}$ also noted that outcome of surgery was determined primarily by physical factors. The failure to find postoperative differences between cases and non-cases in taking analgesia, staying off work, and reporting atypical symptoms could suggest that reduction of distress postoperatively leads to reduction in these manifestations of abnormal illness behaviour.

This study confirms that the illness attitude scale of Kellner was not clearly correlated with psychiatric disorder (unlike the illness behaviour questionnaire, $\mathrm{IBQ}^{20}$ ); but it still did not predict outcome. It seems from this study that attitudes to illness and psychological disorder are separate dimensions.

\section{Conclusion}

This study has shown a high prevalence of psychiatric disorder among preoperative patients with cervical radiculopathy and myelopathy. The model that this psychological disorder is secondary to severity of organic pathology and physical disablement was not supported. However, it was the case that patients with psychiatric disorder had more pain, and they also engaged in behaviours indicative of abnormal illness behaviour. It is suggested that this abnormal illness behaviour may develop secondary to the depressive illness.

Neither psychiatric disorder nor attitudes to illness influenced the outcome of surgery. Further research is needed to determine the psychological and physical predictors of outcome of surgery.

We thank the consultant neurosurgeons Mr RAC Cowie, $\mathrm{Mr} \mathrm{R}$ Jones, Mr C West, Mr R Lye, Mr PL Richardson, Mr FA Strang, and Mr JRS Leggate who kindly agreed to inclusion of their and Mr JRS Leggate who kindly agreed to inclusion of their
patients in the study, and also their medical, nursing, and patients in the study, and also their medical, nursing, and
administrative staff who were so helpful. Thanks also to the administrative staff who were so helpful. Thanks also to the patients themselves who gave up their time to participate in this
study. We are grateful to Mrs B Tomenson, Mr G Dunn, and study. We are grateful to Mrs B Tomenson, Mr G Dunn, and Mrs M Leese for statistical advice, and to Mr G Der for help with analysing the SCAN data. This work was carried out by RET while in a research registrar post supported by the Wellcome Foundation.

1 Love AW, Peck CL. The MMPI and psychological factors in chronic low back pain: a review. Pain 1987;28:1-12.

2 Hurme M, Alaranta $H$. Factors predicting the result of surgery for lumbar intervertebral disc herniation. Spine 1987; 12:933-8.

3 Oostdam EMM, Duivenvoorden HJ. Predictability of the result of surgical intervention in patients with low back pain. F Psychosom Res 1983;27:273-81.

4 Baumhackl E, Oberhummer J, Sunder-Plassman M, Zapotoczky HG, Zaunbauer F. Psychichische Storungen bei zervikalen Bandscheibenschaden und Osteeochondrosen. Psychiatria Clin 1978;11:163-9.

5 Ehni F. Cervical arthrosis diseases of cervical motion segments. Chicago: Chicago Medical Publishers, 1984.

6 Spengler DM, Quellette EA, Battie M, Zeh J Elective discectomy for herniation of a lumbar disc. 7 Bone foint Siscectomy for herniation

7 Roberts N, Smith R, Bennett S, Cape J, Norton R, Kilburn Roberts N, Smith R, Bennett S, Cape J, Norton R, Kilburn P. Health beliefs and rehabilitation aft
surgery. $\mathcal{F}$ Psychosom Res 1984;28:139-44.

8 Waddell G, Morris EW, Di Paola MP, Bircher M, Finlayson $D$. A concept of illness tested as an improved basis for surgical decisions in low back disorders. Spine 1986;11:712-7.

9 Main CJ, Waddell G. A comparison of cognitive measures in low back pain: statistical structure and clinical validity at initial assessment. Pain 1991;46:287-98.

10 Creed F. Psychological disorders in rheumatoid arthritis: a growing consensus? Ann Rheum Dis 1990;49:808-12.

11 World Health Organisation. SCAN: schedules for clinical assessment in neuropsychiatry version 1. Geneva: WHO, 1992.

12 Melzack R. The short-form McGill pain questionnaire. Pain 1987;30:191-7.

13 Patrick D. Funtional limitations profile: document describing the use of the funtional limitations profile, a British version of the sickness impact profile. 1987. Available from the author, $\mathrm{Dr}$ sickness impact profile. 1987. Available from the author, Dr D Patrick, Department of Health Services, SC-37, School of Public Health and Community

14 Follick MJ, Smith TW, Ahern DK. The sickness impact profile: a global measure of disability in chronic low back pain. Pain 1985;21:67-76.

15 Kellner R. Hypochondriasis and somatization. FAMA 1987; 258:2718-22.

16 Wing JK, Mann SA, Leff JP, Nixon JM. The concept of a "case" in psychiatric population surveys. Psychol Med 1978;8:203-17.

17 Feldman E, Mayou R, Hawton K, Ardern M, Smith EB. Psychiatric disorder in medical in-patients. $O \mathcal{F} \mathrm{Med} 1987$; 63:405-12

18 Krishnan KRR, France RD, Pelton S, McCann UD, Davidson J, Urban BJ. Chronic pain and depression II. Symptoms of anxiety in chronic low back pain patients and 289-94.

19 Radanov BP, Di Stefano G, Schnidrig A, Ballinari P. Role of psychological stress in recovery from common whiplash. Lancet 1991;338:712-5. 
20 Pilowsky I, Spence NO. Manual for the illness behaviour questionnaire (IBQ). Adelaide, South Australia: University of Adelaide, 1981

21 Clements DH, O'Leary PF. Anteriror cervical discetomy and fusion. Spine 1990;15:1023-5.

2 Herkowitz HN, Kurz LT, Overholt DP. Surgical management of cervical soft disc herniation. A comparison between the anterior and posterior approach. Spine 1990;15:1026-30.

23 Gore DR, Sepic SB. Anterior cervical fusion for degenerated or protruded discs. Spine 1984;9:667-71.

24 Jeffreys RV. The surgical treatment of cervical myelopathy due to spondylosis and disc degeneration. I N Neurol Neurosurg Psychiatry 1986;49:353-61.

\section{HISTORICAL NOTES}

\section{Wilson's disease}

In Kinnier Wilson's textbook,${ }^{1}$ he writes about the disease that bears his name: "My monograph of 1912 described a disease unknown to the medical profession at that time". While summarising the essential features he emphasises the familial but not congenital nature of the illness, which lasted a few months in acute cases, many years in chronic cases.

Wilson's paper, ${ }^{2}$ the basis of his MD thesis, “. . . contained references to six old and previously obscure cases (none later than 1890), and recorded four of my own in three of which autopsy revealed typical lenticular lesions as well as cirrhosis of the liver."

Wilson acknowledged his indebtedness to Gowers who he said described, "the first two recorded cases of the disease ...." Gowers, in $1888,{ }^{3}$ had reported:

"A ten year old boy with a brother and three other relations having suffered maladies resembling chorea. The boy suffered from tonic spasm which was continuous ... affecting the face producing a constant peculiar smile. The tongue was pressed back against the palate in such a manner as to impede swallowing and prevent speech. The arms were extended, pronated and rotated inwards, .... fingers extended and slowly moved in the irregular way characteristic of athetosis. The legs were extended . . . feet overextended in talipes equino-varus. He died within seven months. Autopsy showed neither naked eye nor microscopic abnormality in the central nervous system."

Eighteen years later Gowers provided ${ }^{4}$ the full histories of the 10 year old Sydney M and his 15 year old sister Charlotte, noting:

"The liver was "firm, hard and lobular and was evidently sclerosed." His sister developed a similar illness. " . . .lip hanging down and was easily excited ... as well as having movements similar to those of her brother."

Wilson acknowledged other suspected cases. Ormerod described bilateral putaminal softenings in a "Case of Cirrhosis of the liver in a boy with obscure and fatal nervous symptoms"; Homén reported a "Peculiar Disease occurring in three members of a family in the form of a progressive dementia probably Lues hereditaria tarda" (sic). However, Wilson strenuously discounted those instances of 'pseudosclerosis' described by Westphal and Strumpell that were "non specific, with no evidence of liver disease, and heterogeneous": a view confirmed later by Greenfield.

A full description is to be found in his paper and his textbook ${ }^{1}$ which includes an account of the corneal ring first reported by Kayser in a case diagnosed as multiple sclerosis, then by Fleischer who realised their diagnostic significance. He continues:

"Initial jaundice is fairly often specified in case-reports, together with ascites perhaps, yet customary symptoms and signs of cirrhosis very seldom occur indeed."

He mentions terminal haematemesis in one case, and notes:

"more usual is swelling of the spleen, enough to render it palpable ... The clinical features of an advancing case is highly characteristic. With mouth often held open, and a stereotyped smile, or, if not laughing or smiling, a vacant or fatuous look, the patient sits and leans to one or the other side, or back, all four limbs agitated by tremor, mostly quick and rather fine; fingers and hands are contracted in flexion, trunk is held stiffly, and willed movements are slowly performed, to the accompaniment of wilder tremulousness. Though saliva may drip from the parted lips and facies almost silly, the eyes are alert and intelligent. Youth may impart a curiously complacent aspect to the features. Fluidity and fixity of symptoms are both evident to the observer; tremors wax and wane, leave one part for another, or alter their type in the same segment according as it is being used or not, but behind the changing phenomena is a general postural stiffness and contraction-attitude, while the physiognomy, too, is apt to become set."

The salient features he summarises as follows:

"A unique feature is the underlying combination of cerebral and visceral lesions, the former consisting (chiefly) in bilateral softening or degeneration of lenticular nucleus (putamen and caudate) and to a less degree of globus pallidus, the latter in hepatic cirrhosis. Without this liver disease, seldom if ever disclosed during life (unless by one or other functional test) no case can be admitted to this category. The clinical syndrome comprises involuntary movements, mostly tremulous but sometimes athetoid or spasmodic, rigidity, dysarthria, dysphagia, emotional overaction (spastic smiling, etc.) and at times mental disorder . . .; in a pure case pyramidal symptoms are lacking. It forms, in brief, a syndrome of extrapyramidal disease."

His ideas about its aetiology show his frustrations with the limitations of available knowledge. He refers to the classic Eck's fistula as establishing a link between liver and brain; and he observes:

"that the liver first becomes affected, that the lenticular lesions follow, and that this hepatitis has something to do with the continuance of toxic effects." $\mathrm{He}$ considered toxic metallic poisons, but "the evidence is scant."

Wilson died of cancer in 1939 shortly before the publication of his magnum opus, and before the discoveries of the defect of caeruloplasmin by Scheinberg in 1952 with consequent copper overloading of the liver, cornea, and brain. His enquiring mind would have been fascinated by knowledge of the autosomal recessive gene linked to markers on chromosome $13 . \mathrm{He}$ would indeed have been gratified by the efficacy of penicillamine shown by Walshe and Yealland in 1956 and later by the effects of trientine and zinc. ${ }^{5}$

J M S PEARCE 304 Beverley Road, Anlaby, East Yorks

HU10 $7 B G, U K$

1 Wilson SAK. Neurology. London: Edward Arnold, 1940;2:806-31.

2 Wilson SAK. Progressive lenticular degeneration: a familial nervous disease associated with cirrhosis of the liver. Brain 1912;34:295-509.

3 Gowers WR. Tetanoid chorea. In: A manual of disease of the nervous system. London: Churchill, 1888;2:656.

4 Gowers WR. On tetanoid chorea and its association with cirrhosis of the liver. Reviews of Neurology and Psychiatry 1906;4:249-58.

5 Walshe JM, Yealland M. Wilson's disease: the problem of delayed diagnosis. F Neurol Neurosurg Psychiatry 1992;55: 692-6. 